\title{
Isolation of Trypanosoma (Megatrypanum) theileri from Dairy Cattle in Taiwan
}

\author{
Yen-Feng LEE ${ }^{1,2)}$, Ching-Chang CHENG $^{1,2)}$, Nai-Nu LIN ${ }^{1,2)}$, Shih-An LIU ${ }^{3)}$, Kwong-Chung TUNG ${ }^{2 \#}$ and \\ Yung-Tsung $\mathrm{CHIU}{ }^{1,4) * \#}$
}

${ }^{1)}$ Department of Medical Research and Education, Taichung Veterans General Hospital, 160, Sec. 3 Taichung Harbor Road, Taichung $40705,{ }^{2)}$ Department of Veterinary Medicine, National Chung-Hsing University, 250 Kuo-Kuang Road, Taichung 40227, ${ }^{3)}$ Department of Otolaryngology, Taichung Veterans General Hospital, 160, Sec. 3 Taichung Harbor Road, Taichung 40705 and ${ }^{4)}$ Department of Animal Science, National Chung-Hsing University, 250 Kuo-Kuang Road, Taichung 40227, Taiwan

(Received 4 August 2009/Accepted 17 November 2009/Published online in J-STAGE 10 December 2009)

ABSTRACT. Although Trypanosoma (Megatrypanum) theileri, a blood parasite of bovid species, is spread widely throughout the world, it has never been reported in Taiwan. When an anti-coagulated blood sample from febrile dairy cattle was directly smeared, no parasite was observed. However, a highly distinctive morphological feature of trypanosome appeared in baby hamster kidney (BHK) cell culture inoculated with non-thrown blood buffy coat. The different stages and typical ultrastructures of trypanosome were observed in our isolate. The isolate was subsequently identified as T. theileri by species-specific PCR assay (Tth625), 18S rDNA sequencing alignment and internal transcribed spacer of ribosomal genes (ITS) as a marker for molecular phylogenetic analysis. The first $T$. theileri isolate in Taiwan (TWTth1) could be periodically passaged in BHK cell culture for more than one year and retained good re-cryopreservation viability. The BHK culture method would be excellent for diagnostic isolation and maintenance long-term development of this parasite. KEY WORDS: $18 \mathrm{~S}$ rDNA, cattle, culture, T. theileri.

Trypanosoma theileri is assigned to the subgenus Megatrypanum by a classification originally based on its morphology. It was first described in cattle by Theiler, Laveran and Bruce in 1902 (cited in Hoare, 1972) [13, 14]. This species is one of the largest mammalian blood trypanosomes whose kinetoplast is typically situated near the nucleus. Hoare (1972) reclassified all trypanosomes from cattle and buffalo as T. theileri, and proposed that other Megatrypanum isolates from Cervidae, Antilocapridae, Tragulidae and Bovidae, with the exception of goats and sheep, should be classified as $T$. theileri-like [14]. Prevalence of $T$. theileri varies considerably in different countries ranging from 10 to $90 \%$ [14]. The pathogenicity of $T$. theileri remains controversial.

The epimastigote and large trypomastigote forms of $T$. theileri can be revealed in peripheral blood. Epimastigote multiplies in the bloodstream by binary fission [18]. Horsefly (Tabanidae) are considered to be the most important vectors [1]. Owing to the lack of a reliable serological diagnostic method for this species and a typically low parasitemia, cultivation of blood samples is better method for detection. Furthermore, T. theileri can be distinguished from other trypanosomes by PCR-amplified spliced-leader transcript [8], internal transcribed spacer of ribosomal genes (ITS gene) [3], 18S ribosomal DNA [7] and a species specific primer set Tth625a,b [19]. However, the spliced-leader transcript is not an informative phylogenetic marker for long range evolutionary studies of the genus Trypanosoma [8], hence

\footnotetext{
* Correspondence to: Chiu, Y.-T., Department of Education and Research, Taichung Veterans General Hospital, 160, Sec. 3 Taichung Harbor Road, Taichung 40705, Taiwan, Republic of China.

e-mail: ytchiu@vghtc.gov.tw

\# Equal contributions.
}

we amplified and sequenced the other three genes to identify and characterize $T$. theileri isolated from the cattle in Taiwan 1 (TWTth1) in the current study.

T. theileri has been reported around the world [12, 22, 31] and continues to be reported in cattle in Europe [5, 9, 27], Australia [29], Africa [24], North and South America [6, 15, 19], Asia [21, 23] and most recently in Spain [28]. In Asia, T. theileri has been observed in Russia, Indo-china, Malaya (Singapore), China, Hong Kong, Indonesia, Philippines, Korea and Japan [13], but not in Taiwan. To our knowledge, this is the first report of $T$. theileri in Taiwan.

In this study, T. theileri was directly isolated and characterized from the cattle in southeastern Taiwan by routine diagnostic baby hamster kidney (BHK) cells. To better understand the structure of cultivated isolate, $T$. theileri, both light and electron microscopy were applied. Based on our findings, the long-term replication abilities of $T$. theileri in cell culture will enable researchers to obtain and maintain a substantial supply of the parasite for further studies.

\section{MATERIALS AND METHODS}

Detection, isolation and growth of trypanosomes from dairy cattle: In September 2007, a blood sample from a 3year-old febrile female Holstein cattle was collected at a dairy farm located in Pingtung County (southeastern Taiwan), where has a subtropical climate and favors a high prevalence of vectors throughout the year. There were no newly introduced cattle or pesticide practice at this farm. The sodium citrate $(0.4 \%)$ anticoagulated blood was collected from the caudal vein of the febrile cattle and kept in cold storage during transport to our laboratory. Collected blood buffy coat $(1.0 \mathrm{~m} l$ each) was directly inoculated, with- 

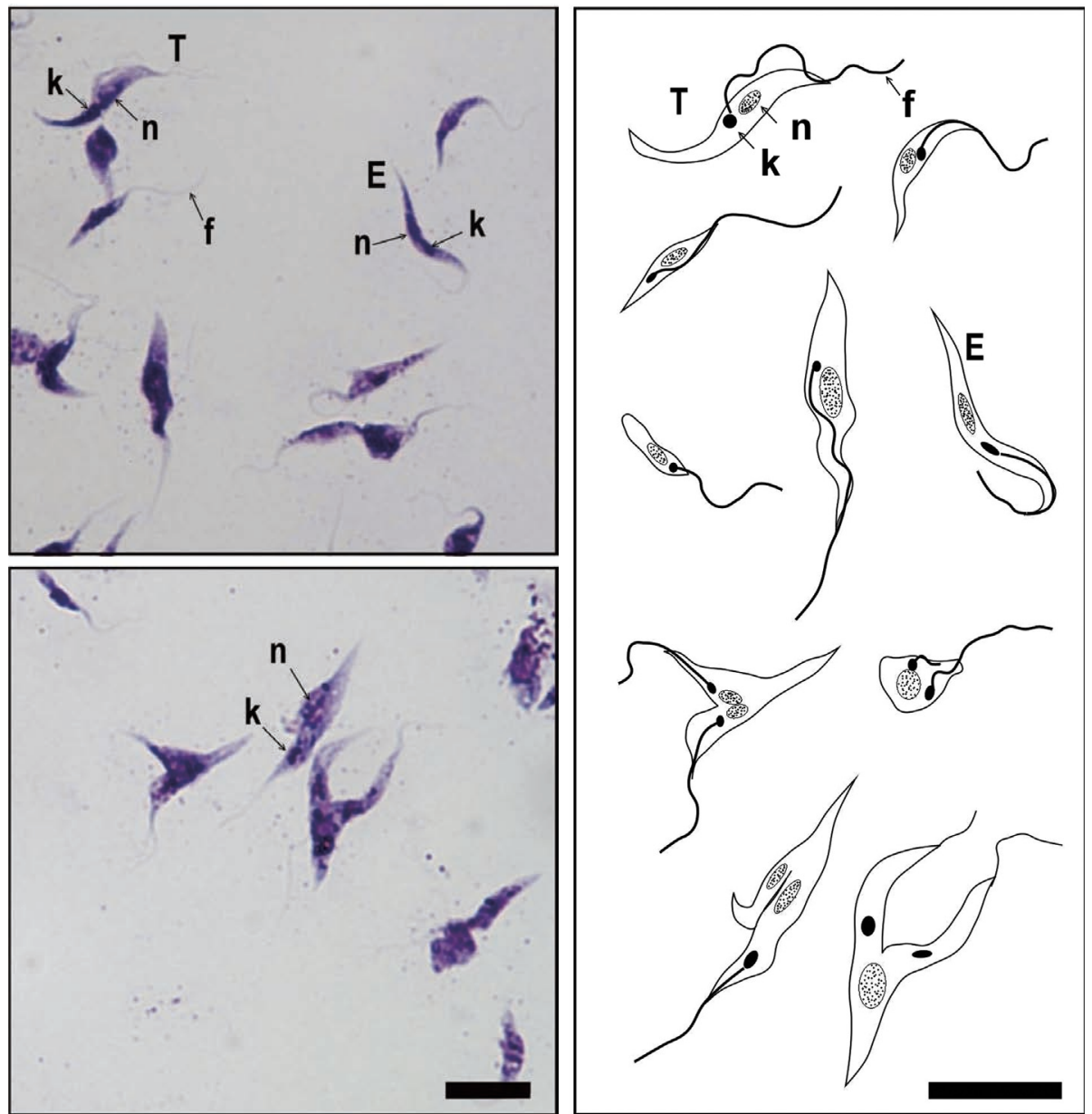

Fig. 1. Light microscopy of TWTth 1 from BHK cell culture supernatant under $37^{\circ} \mathrm{C}, 5 \% \mathrm{CO}_{2}$ growth conditions for ten days (Giemsa stain). Large trypomastigotes, epimastigotes, pear-shaped metacyclic trypomastigotes and long slender formed epimastigotes are shown, but most forms are epimastigote. Bar: $10 \mu \mathrm{m}$. E, epimastigote; $\mathrm{T}$, trypomastigote; f, flagellum; $\mathrm{k}$, kinetoplast; $\mathrm{n}$, nucleus.

out being frozen and thawed, onto monolayers of BHK cells obtained from Bioresource Collection and Research Centre (BCRC) at the Food Industry Research and Development Institute (FIRDI) (Hsinchu, Taiwan) in maintenance medium (Eagle's minimal essential medium supplemented with $10 \%$ heat-inactivated fetal bovine serum (FBS) and PSN Antibiotic Mixture [penicillin, streptomycin, neomycin, Gibco, Carlsbad, CA, U.S.A.) $]$ at $37^{\circ} \mathrm{C}$ in a humidified $5 \% \mathrm{CO}_{2}$ atmosphere with daily monitoring under a reversed microscope at $\times 400$ magnification.

After incubation, the cells were maintained for another two weeks by replacing the medium with fresh maintenance medium every 3-4 days. During the latter two weeks' incubation, trypanosomes propagated and could be observed in the tissue culture flask. The trypanosomes from the primary isolate were cultured for more than one year on BHK cells feeder co-culture with subsequent weekly periodic passages. The inocula suspension containing cells and trypanosomes was scraped from infected monolayer by a rubber policeman for light and transmission electron microscopy.

Light and transmission electron microscopy: The trypanosomes from a culture supernatant underwent low speed centrifugation $(400 \times g, 10 \mathrm{~min})$. They were then placed on smear slides and air dried, followed by Giemsa staining. Stained isolates were observed by light microscopy (Axioskop2, Zeiss, Ontario, CA, U.S.A.) with an oil immersion objective (magnification: $\times 1,000$ ) and images were captured by a digital microscope camera (MacroFire ${ }^{\circledR}$, Optronics, Goleta, CA, U.S.A.). Trypanosome developmental stages were distinguished on the basis of body shape, position of the kinetoplast in relation to the nucleus and arrangement of the flagellum in the body according to Hoare [14].

For transmission electron microscopy, trypanosomes from the culture were fixed in $2.5 \%(\mathrm{v} / \mathrm{v})$ glutaraldehyde, post-fixed with $1 \%(\mathrm{w} / \mathrm{v}) \mathrm{OsO}_{4}$, embedded in epoxy resin, thin sectioned, and examined with a transmission electron microscope (TEM, JEM-1010, JEOL, Tokyo, Japan) as 

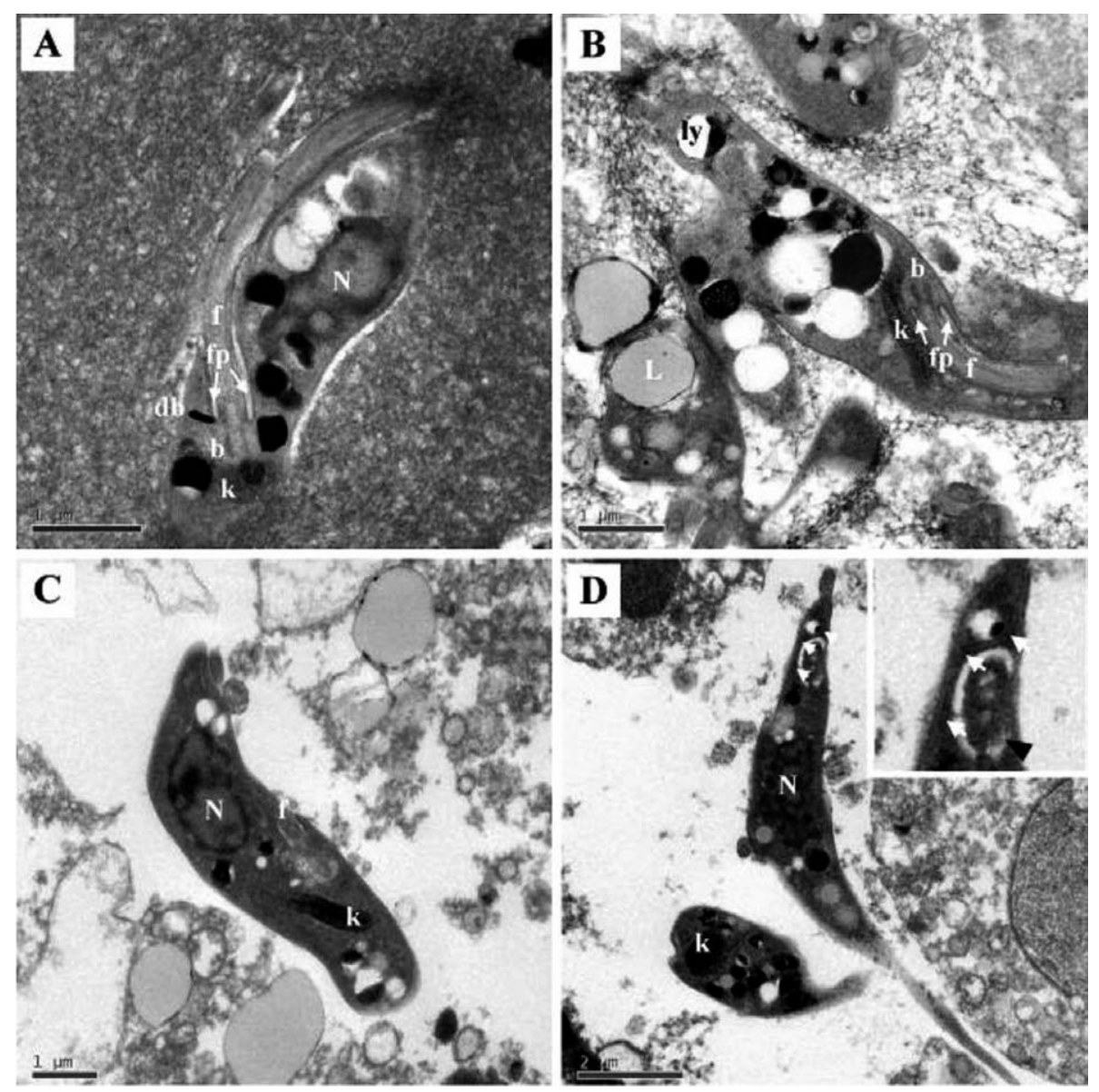

Fig. 2. Ultrastructure of trypomastigote form of TWTth1 grown in BHK coculture. Centrally located nucleus $(\mathrm{N})$, rod-shaped kinetoplast (k), flagellum (f), and flagellar pocket (fp) are shown in longitudinal section. The flagellum emerges from a basal body (b) at the bottom of the flagellar pocket (AC). The DNA fibrils of the kinetoplast are not so compacted and have regular width (B and C). Parasites display numerous acidocalcisomes (ac) with different electron-dense materials and lipid inclusions (L) (A-D). The cytoplasm also contains electron-dense, rod-shaped bodies (A, db), few cisternae of rough endoplasmic reticulum (D, arrows) and autophagic vacuole (D, arrowheads). Bars were $1 \mu \mathrm{m}$ in A-C and $2 \mu \mathrm{m}$ in D. ac, acidocalcisomes; b, basal body; db, electron-dense, rod-shaped bodies; f, flagellum; fp, flagellar pocket; $\mathrm{k}$, kinetoplast; L, lipid inclusions; $\mathrm{N}$, nucleus.

described previously [2].

Cryo-preservation and long-term continuous cultivation: The new cultures of trypanosomes from cattle were BHK cell co-cultured in MEM medium with 10\% heat-inactivated FBS (Invitrogen Carlsbad, CA, U.S.A.) in a humid atmosphere of $5 \% \mathrm{CO}_{2}$ at $37^{\circ} \mathrm{C}$. Cultured trypanosomes were cryopreserved (using $20 \%$ DMSO as a cryopreserver) in liquid $\mathrm{N}_{2}$ [19]. For long-term continuous cultivation, semiconfluent cells were inoculated with trypomastigotes at a proportion of 10:1 cell/parasite and repeat in every 7 dayculture. After 7 days of culture, the medium was removed and the cocultured BHK cells were fixed, followed by Giemsa staining for observation of epimastigotes.

Identification of Trypanosoma by species-specific diagnostic PCR assay: Cultured trypanosomes were washed twice in phosphate buffer solution (PBS) and the pellets obtained were stored at $-20^{\circ} \mathrm{C}$ or immediately processed for genomic DNA extraction using the DNeasy Blood and Tissue Kit (Qiagen Inc., Turnberry Lane Valencia, CA, U.S.A.).

The primers Tth625a (5'-CCG CTG GAG CTA AGA ATA GA-3') and Tth625b (5'-AAT TGC ATA AAC ACA GCT CCC-3') were designed for species-specific PCR amplification (Tth625-PCR) of the $450 \mathrm{bp}$ DNA fragment (Tth625 fragment) described by Rodrigues et al. [19]. The reactions were cycled 30 times as follows: $1 \mathrm{~min}$ at $94^{\circ} \mathrm{C}, 1$ $\min$ at $59^{\circ} \mathrm{C}$ and $1 \mathrm{~min}$ at $72^{\circ} \mathrm{C}$. In the first cycle, the duration at $94^{\circ} \mathrm{C}$ was $3 \mathrm{~min}$, and in the last cycle the duration at $72^{\circ} \mathrm{C}$ was $20 \mathrm{~min}$.

The full length $18 \mathrm{~S}$ ribosomal DNA sequence was analyzed using the forward primer $18 \mathrm{STnF} 2$ (5'-CAA CGA TGA CAC CCA TGA ATT GGG GA-3') and 18STnR3 (5'- 


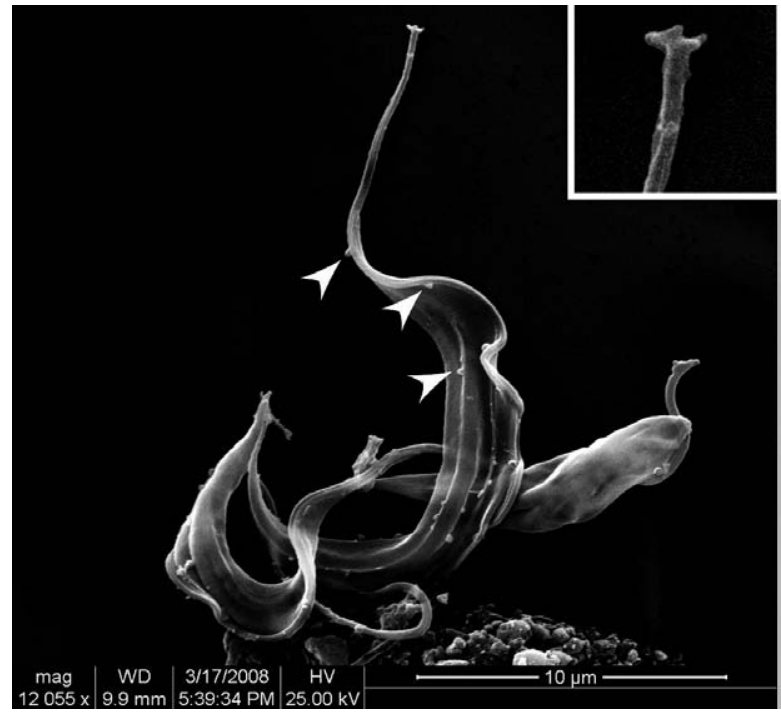

Fig. 3. Scanning electron microscopy of TWTth1 from BHK cell culture supernatant. The large dividing epimastigotes show posterior uncleaved body, undulating membrane, a nodular structure on the cell body (arrowheads) and free flagella with an anchor-like end (up-right panel).

TGC GCG ACC AAT AAT TGC AAT AC-3') as reverse primer [7]. For single PCR amplification, Kin 1 reverse (5'GCG TTC AAA GAT TGG GCA AT-3') and Kin2 forward (5'-CGC CCG AAA GTT CAC C-3') primers were used to anneal internal transcribed spacer of ribosomal genes (ITS) sequence, the conserved spacer between the $5.8 \mathrm{~S}$ and $18 \mathrm{~S}$ ribosomal DNA $[3,17]$. Amplification was performed in 50 $\mu l$ reaction containing $50 \mathrm{ng}$ of DNA, $2.5 \mathrm{U}$ GoTaq DNA polymerase (Promega, Madison, WI, U.S.A.), $0.2 \mathrm{mM}$ dNTP, PCR buffer, $1.5 \mathrm{mM} \mathrm{MgCl} 2$ (Promega), and $200 \mathrm{pM}$ of primer, according to the manufacturer's instructions. Amplicons were separated on 1.8\% agarose gel and stained with 1:10,000 SYBR Safe DNA gel stain solution (Invitrogen).

DNA sequencing and phylogenetic analysis: The PCR fragments described above were purified from agarose gels using GFX PCR DNA and Gel Band Purification kits (GE Healthcare Inc., Buckinghamshire, U.K.) according to the manufacturer's instructions. DNA sequencing was done in both directions with the same primers using an ABI PRISM Big Dye Terminator cycle sequencing kit (Applied Biosystems, Foster city, CA, U.S.A.) and an ABI 3130 genetic analyzer. Phylogenetic analysis of ITS sequences was performed by the neighbor joining method [26] using the CLUSTAL W multiple sequence alignment program (version 1.8.3), Tree View (version 1.6.6) for constructing the phylogenetic tree, and NCBI/BLAST (http:// blast.ncbi.nlm.nih.gov/Blast.cgi).

\section{RESULTS}

Detection, isolation and culture features of blood trypa- nosomes: Trypanosome was isolated in the sick cattle at a dairy farm in southeastern Taiwan after 10 days' BHK cell culture. Trypanosome from the culture was initially observed during the second passage in BHK cells at day 10 , which revealed a large number of motile, flagellated organisms. Microscopy, PCR and sequence analyses showed that the parasite was $T$. theileri and was designated as $T$. theileri isolate from cattle in Taiwan 1 (TWTth1). Under these growth conditions, two stages of TWTth1, trypomastigote $(2.1-3.5 \times 24.1-30.7 \mu \mathrm{m})$ and epimastigote forms $(1.8-2.0$ $\times 16.3-30.0 \mu \mathrm{m})$, were shown. An epimastigote had a kinetoplast anterior to the nucleus (Fig. 1), whereas trypomastigote had a kinetoplast posterior to the nucleus (Fig. 1), and most culture forms were epimastigote. Epimastigotes were occasionally observed multiplying asexually by binary fission (Fig. 1). In addition, transition forms of highly variable body shape and flagellum length were also revealed, such as pear-shaped metacyclic trypomastigotes and long slender forms of epimastigote.

Transmission electron microscopy observation: Ultrastructural appearance of a random sample of TWTth1 trypanosomes growing in BHK cell co-culture revealed a centrally located nucleus, rod-shaped kinetoplast, a flagellum with flagellar pocket, basal body and endoplasmic reticulum (Fig. 2). The kinetoplast was typically broad in width with a network of DNA fibrils not very condensed and always adjacent to the base of flagellum but varied in the position (Fig. 2A-C, k). The flagellum (Fig. 2A-C, f) emerged from a basal body (Fig. $2 \mathrm{~A}$ and $2 \mathrm{~B}, \mathrm{~b}$ ) at the bottom of the flagellar pocket (Fig. $2 \mathrm{~A}$ and $2 \mathrm{~B}$, fp). The electron dense vacuoles (acidocalcisomes) varied in amount were observed, frequently on only one side of the membranes, but somtimes they filled the cytoplasm (Fig. 2, ac). In some vacuoles, the electron dense material was empty, and only a thin dense ring below the membrane was observed (Fig. 2, ac). Some organisms contained electrondense, rod-shaped bodies (Fig. 2A, db), as observed previously in $T$. theileri by Herbert [12]. The cytoplasm also contained lipid inclusions (Fig. 2B, L), few cisternae of rough endoplasmic reticulum (Fig. 2D, arrows) and autophagic vacuole (Fig. 2D, arrowheads).

Scanning electron microscopy observation: Scanning electron microscopic observation of TWTth1 from the culture supernatant not only showed large binary dividing epimastigotes with posterior uncleaved cell body and undulating membrane (Fig. 3) but also revealed a markedly nodular structure on the cell body (Fig. 3, arrowheads) and anchor-like structure at the end of free flagella (Fig. 3, upright panel), which has not been described in previous studies of $T$. theileri and whose function is currently unknown. Furthermore, epimastigote during asexual binary fission was also observed.

Specific PCR assay of Trypanosome isolate-TWTth1 and phylogeny based on ITS sequences: The cultured trypanosomes were positively identified using $T$. theileri specific PCR (Tth625-PCR) in amplicons 472 bp for TWTth1 (Fig. 4A). A comparison of $T$. theileri with DNA (Rodrigues A) 


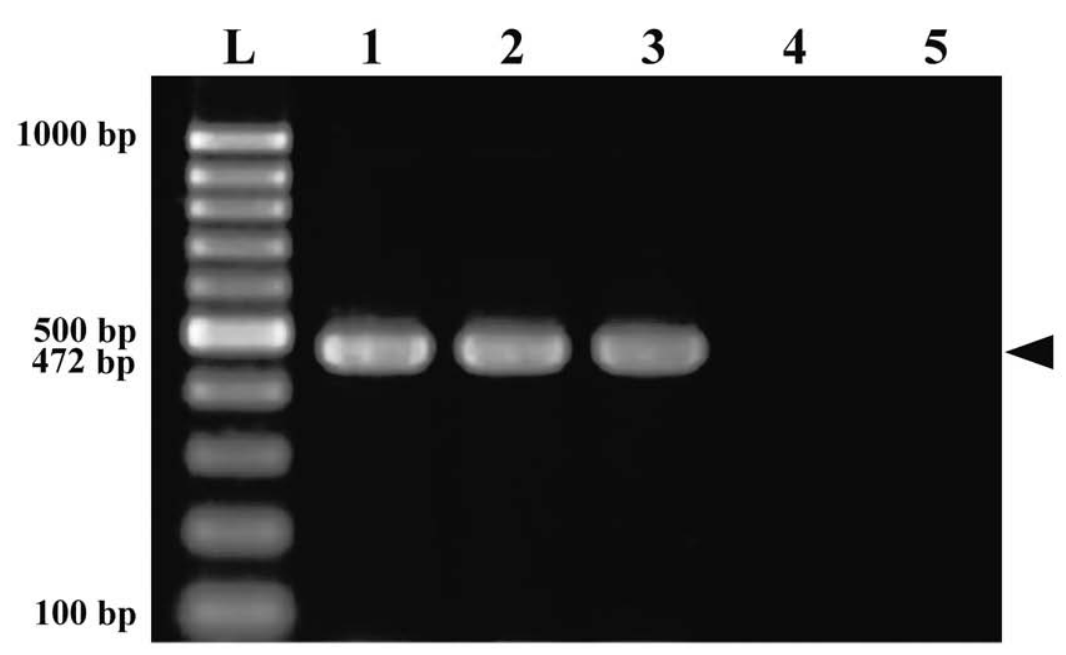

A

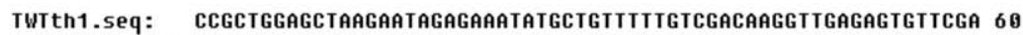
AF537201.seq: CCGCTGGAGCTAAGAATAGAGAAATATGCTGITITTGTCGACAAGGITGAGAGTGTTCGA 60 AF537202.seq: CCGCTGGAGCTAAGAATAGAGAAATATGCTGIIITIGTCGACAAGGTTGAGAGTGITCGA 60

TWTth1.seq: CAGCGAATAGCGCAGTTGAGCCGCTGGCCACCATCCCCAGTATTAATGGAATATAAGGAT 128 AF537201.seq: CAGCGAATAGCGCAGTTGAGCCGCTGGCCACCATCCCCAGTATTAATGGAATATAAGGAT 128 AF537202.seq: CAGCGAATAGCGCAGTTGAGCCGCTGGCCACCATCCCCAGTATTAATGGAATATAAGGAT 128

TUTth1.seq: GTGCGCATITCACCACGITATCITGITCTCACAACAACGIITCCIGTAGATGIGGGGIT 18 AF537201.seq: GTGCGCATITCACCACGTTATCTIGITCTCACAACAACGITTCCTGTAGATGTGGAGTIG 180 AF537202.seq: GTGCGCATITCACCACGTTATCTTGTTCTCACAACAACAITTCCTGTAGATGTGGAGTIG 188

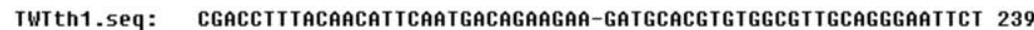
AF537201.seq: CGACCTITACAACATICAATGACAGAAGAAAGATGCACGTGTGGCGTTGCAGGGAATTCT 240 AF537282.seq: CGACCTITACAACAITCAATGACGGAAGAA-GATGCACGTGTGGCGETGCAGGGAATTCT 239

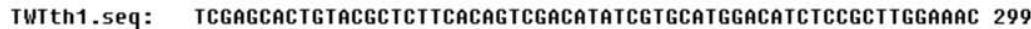
AF537201.5eq: -CGAGCACTGTACGCTCITCACAGTCGACATATCGIGCATGGACATCTCCGCIIGGAAAC 299 AF537202.seq: ICGAGCACTGTACGCTCTTCACAGTCGACATATCGTGCATGGACATCTCCGCITGGAAAC 299

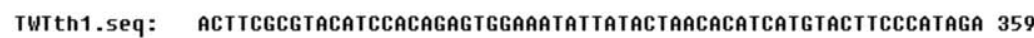
AF537201.5eq: ACTICGCGTACATCCACAGAGTGGAAATATTATACTAACACATCATGTACTTCCCATAGA 359 AF537202.seq: ACTICGCGTACATCCACAGAGTGGAAATATTATACTAACACATCATGTACTTCCCATAGA 359

TWTth1.seq: IITGITGTACCCTCCAGTGATGITGGGGagaAGCITGGCACTGITGTGCCCCAGAGat 419 AF537201.seq: TITGITIGTACCCTCCAGTGATGITGGGCGAGAAGCTTGGCACTGITGTGCCCCAGAGAT 419 AF537202.5eq: IITGITIGTACCCTCCAGTGATGTIGGGCGAGAAGCTTGGCATTGTTGTGCCCCAGAGAT 419

TWTth1.seq: AAAGCGTAACTCTGCIITTGATTATAGTGC 449 AF537201.seq: AAAGCGTAACTCTGCTITTGATTATAGTGC 449 AF537202.seq: AAAGCGTAATICTGCTITTGATTATAGTGC 449

B

Fig. 4. Detection and alignment of T. theileri DNA from the cultured TWTth1. (A) Electrophoresis of three random TWTth 1 samples in $1.8 \%$ agarose gel followed by staining with SYBR Safe DNA gel stain solution. The bands of $472 \mathrm{bp} \mathrm{T}$. theileri species-specific PCR-Tth625 assay amplicons are recognized (lanes 1,2,3), while no bands are observed in BHK control cell (lane 4) and neg. medium (lane 5). L: leader. (B) Alignment of the $T$. theileri DNA (Rodrigues A) GenBank Accession No: AF537201, AF537202 and TWTth1 sequences.

[19] GenBank Accession No: AF537201 and AF537202 showed that homology of the present sequence was $99.5 \%$ $(448 / 450)$ and $98.8 \%(445 / 450)$ to those, respectively (Fig. $4 \mathrm{~B})$. An analysis of the amplicons of full length $18 \mathrm{~S}$ ribosomal DNA sequence of TWTth1 using NCBI GenBank showed that TWTth1 was $100 \%$ identical to the positions of
T. theileri GenBank sequences (1941-1289, NCBI accession number AB007814.1). Phylogeny of TWTth1 and related $T$. theileri isolates (Rodrigues A) based on ITS sequences $[3,19,20]$ showed homogeneity, that is, $100 \%$ identical with the Japanese isolate (AB007814) and two Brazilian isolates (AY773707, AY773708), and 97.3 to 


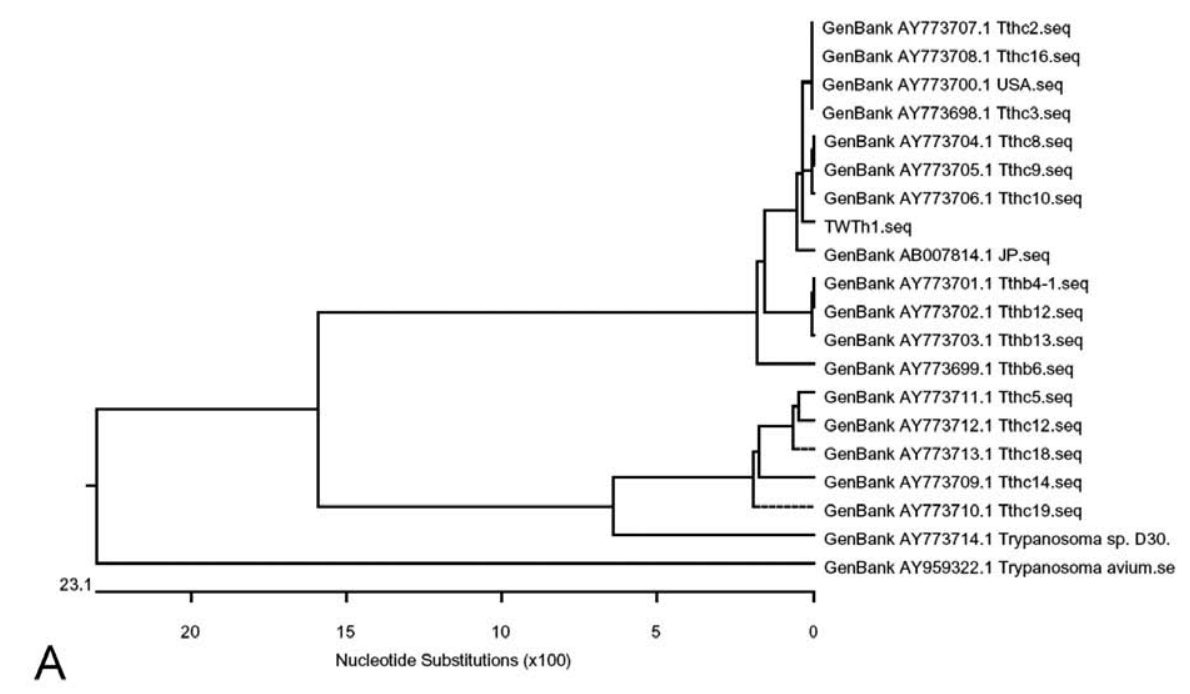

\begin{tabular}{cl} 
Host origin & Country \\
\hline Cattle & Brazil \\
Cattle & Brazil \\
Cattle & USA \\
Cattle & Brazil \\
Cattle & Brazil \\
Cattle & Brazil \\
Cattle & Brazil \\
Cattle & Taiwan \\
Cattle & Japan \\
Buffalo & Brazil \\
Buffalo & Brazil \\
Buffalo & Brazil \\
Buffalo & Brazil \\
Cattle & Brazil \\
Cattle & Brazil \\
Cattle & Brazil \\
Cattle & Brazil \\
Cattle & Brazil \\
Deer & Germany \\
Black Flies & Finland \\
& \\
&
\end{tabular}

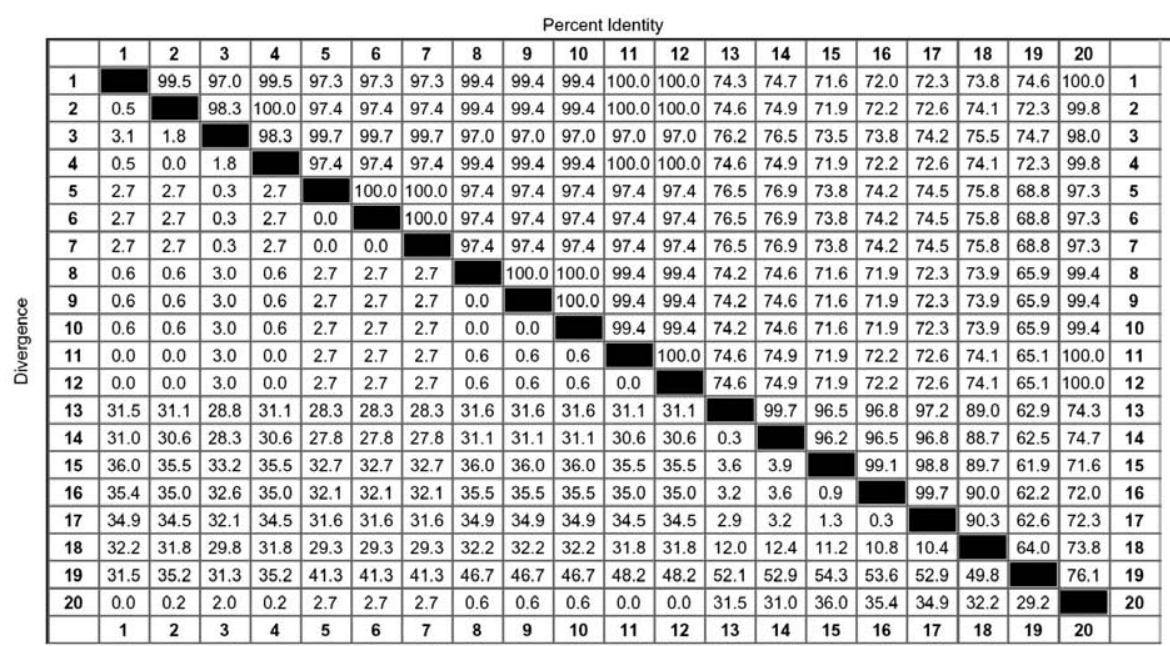

TWTh1.seq

GenBank AY773698.1 Tthc3.seq GenBank AY773699.1 Tthb6.seq GenBank AY773700.1 USA.seq GenBank AY773701.1 Tthb4-1.seq GenBank AY773702.1 Tthb12.seq GenBank AY773703.1 Tthb13.seq GenBank AY773704.1 Tthc8.seq GenBank AY773705.1 Tthc9.seq GenBank AY773706.1 Tthc10.seq GenBank AY773707.1 Tthc2.seq GenBank AY773708.1 Tthc16.seq GenBank AY773709.1 Tthc14.seq GenBank AY773710.1 Tthc19.seq GenBank AY773711.1 Tthc5.seq GenBank AY773712.1 Tthc12.seq GenBank AY773713.1 Tthc18.seq GenBank AY773714.1 Trypanosoma sp. D30. GenBank AY959322.1 Trypanosoma avium.se GenBank AB007814.1 JP.seq

B

Fig. 5. (A) Phylogeny based on ITS sequences and (B) relationships among T. theileri trypanosomes from cattle (Tthc) and water buffalo (Tthb).

98.0\% homological with Brazilian buffalo isolates (Fig. 5).

When diagnostic PCRs (for bovine leukosis virus, bovine herpesvirus type 1 , bovine ephemeral fever virus, bovine coronavirus, bovine parainfluenza virus and bovine viral diarrhea virus) and routine bacterial cultures (for aerobic and anaerobic bacteria) were performed in order to clarify whether any coinfection with other microorganisms existed in this study, all results were negative.

In vitro propagation and long-term continuous cultivation of TWth1 in BHK cell line co-culture system: When the primary isolates were transferred to these semiconfluent mammalian cell monolayers, epimastigotes multiplied intensively in the supernatant and differentiated to trypomastigotes 3-7 days later. Pear-shaped metacyclic trypomastigotes were present in old cultures. No apparent change of morphological properties was observed in this period.
Our results indicated that TWth1 can be propagated and maintained in BHK cell co-culture for more than one year without significant morphological changes. In axenic culture conditions, RPMI medium 1640 (Gibco, Cat No 22400) containing 10\% FBS (Hyclone, Logan, UT, U.S.A., Cat No SH30070.03) induced club-shaped trypanosomes, followed by death after 14 days in cell-free culture (data not shown).

\section{DISCUSSION}

T. theileri can be rarely detected in microscopic examination of the stained smears of peripheral blood [10]. In this study, T. theileri was incidentally isolated from cattle during a routine diagnostic cell culture for clinical virological examination. The cultured trypanosomes were identified as $T$. theileri using diagnostic $T$. theileri specific PCR 
(Tth625), ITS genes region and full length 18S ribosomal DNA sequencing (Figs. 4 and 5).

Further examination revealed numerous elongated organisms that were tapered at both ends and characterized by an undulating membrane and a long flagellum (Fig. 3). The organisms showed various stages of development with different lengths (Fig. 1). Although T. theileri has been reported to be commonly isolated concomitantly with other microorganisms, coinfection was not found in our analyses.

Most infections have a subclinical latency and may persist for several years with no obvious signs of illness. They also show a cryptic and chronic infection, and cannot be revealed by blood smears. Detectable parasitemia is usually associated with mixed infections. Since the endemic status and vector of $T$. theiler $i$ have not been described, these problems in Taiwan should be cleared in future.

Several cell cultures have been examined for subsequent propagation of some cell-free media and hemocultures [19]. As has been previously described, bovine bone marrow [16], human or monkey cells [4, 31, 32], HeLa, human epidermoid (Hep), human embryonic lung (Hel), monkey stable (MS) cell [32], and LLCMK2 (monkey) cells (a common cell line used to culture intracellular protozon such as Toxoplasma) [19] can be used to propagate T. theileri. Hatama et al. [11] isolated a Megatrypanum trypanosome which is closely related to $T$. theileri from a sika deer shortly after death using kidney primary trypsinizating culture, however, subsequent attempts to propagate it in a bovine kidney cell line (Madin-Darby bovine kidney cell) and chicken cell primary culture (chicken embryo fibroblast) were not successful.

In this paper, BHK cell line was used, which is commonly used for routine diagnosis of bovine disease and has never been used to isolate $T$. theileri from cattle. Compared with cell lines used in previous studies, isolation of T. theileri with BHK cell line was more convenient as it was available for both primary and continuous cultivation and yielded a more stable long-term culture.

The organisms were initially observed during the second passage in BHK cells at day 10 , and examination of wet mounts of the culture fluid by light microscopy (magnification: $\times 200$ ) led to tentative identification of trypanosomes. The new T. theileri isolate (TWTth1) showed different developing stages, including trypomastigotes, epimastigotes, pear-shaped metacyclic trypomastigotes and long slender forms of epimastigote in BHK cells culture (Fig. 1). This indicates that cell cultured TWTth1 isolate is a pleomorphic line. TWTth1 has been propagated in vitro for longer than one year in BHK cell cultures. However, in axenic culture conditions, RPMI medium 1640 containing $10 \%$ FBS maintained the trypanosomes transiently and induced club-shaped cells, followed by death after 14 days in cell-free culture (data not shown).

In the salivary glands of an infected tsetse fly, the epimastigotes of $T$. brucei attach to the epithelium through an elaboration of the flagellar membrane [25]. In the renal cell culture, epimastigotes and trypomastigotes of Megatry- panum trypanosome isolated from sika deer attach to the feeder cells by their flagella [11]. This finding was also revealed using the culture system in our current study (Fig. 1). Furthermore, different replicating and differentiating forms of the trypanosomes were observed to attach the culture cells. Since attachment and differentiation of trypanosomes in the salivary gland are essential steps to complete the repetition of life cycle, these may explain why trypanosomes can be cultured for long-period in this cell culture system. Further investigation would also warrant that whether in vitro cell co-culture system can be used as a model for attachment, replication and differentiation of trypanosomes in the gut epithelium of vectors.

ACKNOWLEDGMENT(S). This work was support by grants from Taichung Veterans General Hospital (TCVGH967307B, -977325D) and the Bureau of Animal and Plant Health Inspection and Quarantine (96AS-14.6.1-BQ-B3) in Taiwan.

\section{REFERENCES}

1. Böse, R. and Heister, N. C. 1993. Development of Trypanosoma (Megatrypanum) theileri in tabanids. J. Eukaryot. Microbiol. 40: 788-792.

2. De Carvalho, E. A., Andrade, P. P., Silva, N. H., Pereira, E. C. and Figueiredo, R. C. 2005. Effect of usnic acid from the lichen Cladonia substellata on Trypanosoma cruzi in vitro: an ultrastructural study. Micron 36: 155-161.

3. Desquesnes, M., McLaughlin, G., Zoungrana, A. and Dávila, A. M. 2001. Detection and identification of Trypanosoma of African livestock through a single PCR based on internal transcribed spacer 1 of rDNA. Int. J. Parasitol. 31: 610-614.

4. Dirie, M. F., Bornstein, S., Wallbanks, K. R., Stiles, J. K. and Molyneux, D. H. 1990. Zymogram and life-history studies on trypanosomes of the subgenus Megatrypanum. Parasitol. Res. 76: 669-674.

5. Doherty, M. L., Windle, H., Voorheis, H. P., Larkin, H., Casey, M., Clery, D. and Murray, M. 1993. Clinical disease associated with Trypanosoma theileri infections in a calf in Ireland. Vet. Rec. 26: 653-656.

6. Farrar, R. G. and Klei, T. R. 1990. Prevalence of Trypanosoma theileri in Lousiana cattle. J. Parasitol. 76: 734-736.

7. Geysen, D., Delespaux, V. and Geerts, S. 2003. PCR-RFLP using Ssu-rDNA amplification as an easy method for speciesspecific diagnosis of Trypanosoma species in cattle. Vet. Parasitol. 110: 171-180.

8. Gibson, W., Bingle, L., Blendeman, W., Brown, J., Wood, J. and Stevens, J. 2000. Structure and sequence variation of the trypanosome spliced leader transcript. Mol. Biochem. Parasitol. 107: 269-277.

9. Greco, A., Loria, G. R., Dara, S., Luckins, T. and Sparagano, O. 2000. First isolation of Trypanosoma theileri in Sicilian cattle. Vet. Res. Commun. 24: 471-475.

10. Griebel, P. J., Gajadhar, A. A., Babiuk, L. A. and Allen, J. R. 1989. Trypanosoma theileri associated with T-lymphocytes isolated from a latently infected cow. J. Protozool. 36: 415421.

11. Hatama, S., Shibahara, T., Suzuki, M., Kadota, K., Uchida, I. and Kanno, T. 2007. Isolation of a Megatrypanum trypanosome from sika deer (Cervus nippon yesoensis) in Japan. Vet. 
Parasitol. 149: 56-64.

12. Herbert, I. V. 1964. Trypanosoma theileri, Laveran, 1902. A cosmopolitan parasite of cattle. Vet. Bull. 34: 563-570.

13. Hoare, C. A. 1964. Morphological and taxonomic studies on mammalian trypanosomes. X. Revision of the systematics. $J$. Protozool. 11: 200-207.

14. Hoare, C. A. 1972. Subgenus Megatrypanum. pp. 123-141. In: The Trypanosomes of Mammals: A Zoological Monograph, Blackwell Scientific Publications, Oxford.

15. Kennedy, M. J. 1988. Trypanosoma theileri in cattle of central Alberta. Can. Vet. J. 29: 937-938.

16. McHolland-Raymond, L. E., Kingston, N. and Trueblood, M. S. 1978. Continuous cultivation of Trypanosoma theileri at $37^{\circ} \mathrm{C}$ in bovine cell culture. J. Protozool. 25: 388-394.

17. McLaughlin, G. L., Ssenyongo, S. S., Nanteza, E., RubaireAkiki, Wafula, O., Hansen, R. D., Vodkin, M. H., Novak, R. J., Gordon, V. R., Montenegro-James, S., James, M., Aviles, H., Armijos, R., Santrich, C., Weigle, K., Saravia, N., Wozniak, E., Gaye, O., Mdachi, R., Shapiro, S. Z., Chang, K. P. and Kakoma, I. 1996. PCR based detection and typing of parasites. pp. 261-287. In: Parasitology for the 21st Century (Chapter 25) (Azcel, M. A. and Alkan, M. Z. eds.), CAB International, Wallingford.

18. Reichenow, E. 1940. Ostafrikanische Beobachtungen an Trypanosomiden. Arch. f. Protistenk. 94: 267-287.

19. Rodrigues, A. C., Campaner, M., Takata, C. S., Dell' Porto, A., Milder, R. V., Takeda, G. F. and Teixeira, M. M. 2003. Brazilian isolates of Trypanosoma (Megatrypanum) theileri: diagnosis and differentiation of isolates from cattle and water buffalo based on biological characteristics and randomly amplified DNA sequences. Vet. Parasitol. 116: 185-207.

20. Rodrigues, A. C., Paiva, F., Campaner, M., Stevens, J. R., Noyes, H. A. and Teixeira, M. M. 2006. Phylogeny of Trypanosoma (Megatrypanum) theileri and related trypanosomes reveals lineages of isolates associated with artiodactyl hosts diverging on SSU and ITS ribosomal sequences. Parasitology 132: $215-224$
21. Samad, M. A. and Shahidullah, M. 1985. Trypanosoma theileri infection in cattle of Bangladesh. Ind. Vet. J. 62: 903-905.

22. Schlafer, D. H. 1979. Trypanosoma theileri: a literature review and report of incidence in New York cattle. Cornell Vet. 69: 411-425.

23. Seifi, H. A. 1995. Clinical trypanosomosis due to Trypanosoma theileri in a cow in Iran. Trop. Anim. Health Prod. 27: 93-94.

24. Tarimo-Nesbitt, R. A., Golder, T. K. and Chaudhury, M. F. 1999. Trypanosome infection rate in cattle at Nguruman, Kenya. Vet. Parasitol. 81: 107-117.

25. Tetley, L. and Vickerman, K. 1985. Differentiation in Trypanosoma brucei: host-parasite cell junctions and their persistence during acquisition of the variable antigen coat. $J$. Cell Sci. 74: 1-19.

26. Thompson, E. A. and Neel, J. V. 1997. Allelic disequilibrium and allele frequency distribution as a function of social and demographic history. Am. J. Hum. Genet. 60: 197-204.

27. Verloo, D., Brandt, J., Van Meirvenne, N. and Büscher, P. 2000. Comparative in vitro isolation of Trypanosoma theileri from cattle in Belgium. Vet. Parasitol. 89: 129-132.

28. Villa, A., Gutierrez, C., Gracia, E., Moreno, B., Chacón, G., Sanz, P. V., Büscher, P. and Touratier, L. 2008. Presence of Trypanosoma theileri in Spanish Cattle. Ann. New York Acad. Sci. 1149: 352-354.

29. Ward, W. H., Hill, M. W., Mazlin, I. D. and Foster, C. K. 1984. Anaemia associated with a high parasitaemia of Trypanosoma theileri in a dairy cow. Vet. J. 61: 324 .

30. Wells, E. A. 1971. Studies on Trypanosoma theileri-like trypanosomes of cattle. I. Culture and storage of isolation. Br. Vet. J. 127: 466-475.

31. Wells, E. A. 1976. Subgenus Megatrypanum. pp. 257-275. In: Biology of the Kinetoplastida (Lumsden, W. H. R. and Evans, D. A. eds.), Academic Press, London.

32. Wink, M. 1979. Trypanosoma theileri: in vitro cultivation in tsetse fly and vertebrate cell culture systems. Int. J. Parasitol. 9: 585-589. 